\title{
LOCAL MODES OF TRANSITION METAL IONS (Mn, Fe, Co) IN MERCURY CHALCOGENIDES
}

\author{
W. Szuszkiewicz, K. Dybko, E. Dynowska, B. Witkowska \\ Institute of Physics, Polish Academy of Sciences \\ Al. Lotników 32/46, 02-668 Warszawa, Poland \\ M. JouAnNe AND C. JULIEN
}

Laboratoire de Physique des Solides de l'Université Pierre et Marie Curie 4, pl. Jussieu, 75252 Paris, Cedex 05, France

Optical phonons in mercury chalcogenides doped with selected transition metal ions are investigated by infrared reflectivity and Raman scattering measurements performed at helium temperatures. The results obtained for $\mathrm{Hg}_{1-x} \mathrm{Fe}_{x} \mathrm{Se}, \mathrm{Hg}_{1-x} \mathrm{Co}_{x} \mathrm{Se}, \mathrm{Hg}_{1-x} \mathrm{Fe}_{x} \mathrm{~S}$ and $\mathrm{Hg}_{1-x} \mathrm{Co}_{x} \mathrm{~S}$ mixed crystals demonstrate the significant influence of the $3 d$ electron correlation effects and/or $s p-d$ hybridization on the transition metal ion local mode frequency.

PACS numbers: $63.20 . \mathrm{Pw}, 71.70 . \mathrm{Gm}, 78.30 . \mathrm{Fs}$

Zinc-blende II-VI semimagnetic (diluted magnetic) semiconductors offer a lot of valuable opportunities for different studies due to their interesting electrical, magnetic and optical properties. The lattice dynamics of semimagnetic semiconductors is relatively well known for the wide-gap materials. Recently the systematic studies of the local modes associated with the transition metal ions (TMIs) have been performed for $\mathrm{CdTe}$ and $\mathrm{ZnTe}$ [1]. The investigations of the lattice dynamics for the narrow-gap ternary alloys have been limited up to now to the best known systems $\mathrm{Hg}_{1-x} \mathrm{Mn}_{x} \mathrm{Te}$ [2] and $\mathrm{Hg}_{1-x} \mathrm{Mn}_{x} \mathrm{Se}$ [3].

The purpose of our work is to study the lattice dynamics properties within the same family of the narrow-gap mixed crystals containing various TMIs. The $\mathrm{Hg}_{1-x} \mathrm{M}_{x}$ Se and $\mathrm{Hg}_{1-x} \mathrm{M}_{x} \mathrm{~S}$ (M - TMIs) systems were selected for such investigations. The reason was that the lattice dynamics for $\mathrm{HgSe}$ is relatively well known and HgSe doped with TMIs forms mixed crystals in a wide composition range. On the other hand very recently good quality monocrystals of new semimagnetic semiconductors have been obtained by HgS doping with selected TMIs [4].

All the mixed crystals investigated in this work have been grown by the modified Bridgman method in the Institute of Physics, Polish Academy of Sciences in Warsaw. The crystal structure and chemical composition of the samples were verified by X-ray diffraction, the electron microprobe and independently 
by the energy-dispersive X-ray fluorescence analysis (EDXRF) using a TRACOR $\mathrm{X}$-ray Spectrace 5000 analyzer. For semimagnetic semiconductors based on $\mathrm{HgSe}$ the above-mentioned measurements have been performed on $\mathrm{Hg}_{1-x} \mathrm{Fe}_{x} \mathrm{Se}$ and $\mathrm{Hg}_{1-x} \mathrm{Co}_{x} \mathrm{Se}$ samples containing up to $12 \%$ of $\mathrm{Fe}$ and up to $5 \%$ of $\mathrm{Co}$, respectively. $\mathrm{Hg}_{1-x} \mathrm{Mn}_{x}$ Se ternary alloy was not investigated due to the presence of the appropriate data in the literature [3]. For semimagnetic semiconductors based on $\beta$ - $\mathrm{HgS}$ the measurements mentioned above have been performed on $\mathrm{Hg}_{1-x} \mathrm{Fe}_{x} \mathrm{~S}$ samples containing up to $8 \%$ of $\mathrm{Fe}$ and a few samples containing up to about $2 \%$ of $\mathrm{Co}$ or $\mathrm{Mn}$ were also analyzed.

The infrared reflectivity measurements were performed at $5 \mathrm{~K}$ using a Fourier spectrometer in a wavelength region covering both the lattice excitations and free-carrier plasma edge $\left(100 \div 1500 \mathrm{~cm}^{-1}\right)$. The typical spectra were taken with the instrumental resolution $2 \mathrm{~cm}^{-1}$. All the samples based on $\mathrm{HgSe}$ or $\beta$-HgS compounds investigated in the present work are $n$-type materials with free-carrier concentrations as high as a few times $10^{18} \mathrm{~cm}^{-3}$. The Raman spectra were excited with $\mathrm{Ar}^{+}$laser lines (457.9 nm and $514.5 \mathrm{~nm}$ ), and $\mathrm{Kr}^{+}$laser line $530.9 \mathrm{~nm}$.

The obtained reflectivity spectra are analyzed using the dynamic dielectric function formalism. For the mixed crystals under investigation (except $\mathrm{Hg}_{1-x} \mathrm{Mn}_{x} \mathrm{~S}$ samples) two structures in the reflectivity spectra, corresponding to two TO-phonon excitations, were found. The principal structure results from the $\mathrm{HgSe}$-like or $\beta$-HgS-like TO mode. The detailed analysis of HgSe-like lattice modes can be found in Ref. [5]. The second small structure in the reflectivity spectra results from $\mathrm{HgSe}$ or $\beta$-HgS doping with TMIs. TMI local mode frequencies have been determined from the composition dependence of the appropriate optical mode frequencies. The Fe local mode frequency in HgSe at helium temperature is equal to $(221 \pm 1)$ $\mathrm{cm}^{-1}$, the Co local mode frequency is noticeably higher and is equal to $(229 \pm 1)$ $\mathrm{cm}^{-1}$. The results of Raman spectroscopy measurements performed on $\mathrm{HgSe}$ samples containing more than $3 \%$ of Co or Fe confirm, within experimental error, the values resulting from the infrared reflectivity measurements. The Mn local mode frequency in $\mathrm{HgSe}$ is equal to $218 \mathrm{~cm}^{-1}$ at room temperature [3]. One can expect a slight increase in this value at low temperatures, our rough estimates based on the low temperature data published in Ref. [3] give a value of $(223 \pm 2) \mathrm{cm}^{-1}$. For the second semimagnetic semiconductors family under investigations (mixed crystals based on $\beta$-HgS) the local mode frequency is equal to about $(307 \pm 2) \mathrm{cm}^{-1}$ for $\mathrm{Fe}$ and to $(314 \pm 2) \mathrm{cm}^{-1}$ for Co. We are not able to determine a value of the $\mathrm{Mn}$ local mode frequency due to the low Mn content in our samples accompanied by the high electron concentration $\left(N=4.2 \times 10^{18} \mathrm{~cm}^{-3}\right.$ at $\left.T=4.2 \mathrm{~K}\right)$.

As one can see for both $\beta$-HgS and $\mathrm{HgSe}$ the local $\mathrm{Fe}$ mode frequency is smaller than the local Co mode frequency. The comparison of the local mode frequency for $\mathrm{HgSe}$ and $\beta$-HgS doped with investigated TMIs to the literature data corresponding to wide-gap materials (CdTe, $\mathrm{ZnTe}$, cubic $\mathrm{ZnSe}$ grown by $\mathrm{MBE}$ technique and $\mathrm{ZnS}$ ) is shown in Fig. 1. In this picture the experimental data for $\mathrm{HgTe}$ doped with Mn [2] and for MBE-grown cubic CdSe doped with Mn [11] are not included but they corresponds exactly to the data presented for Mn doped $\mathrm{CdTe}$ and $\mathrm{HgSe}$, respectively. The presented data suggest a possible difference between the investigated II-VI compounds. It seems that for selenides and tellurides 

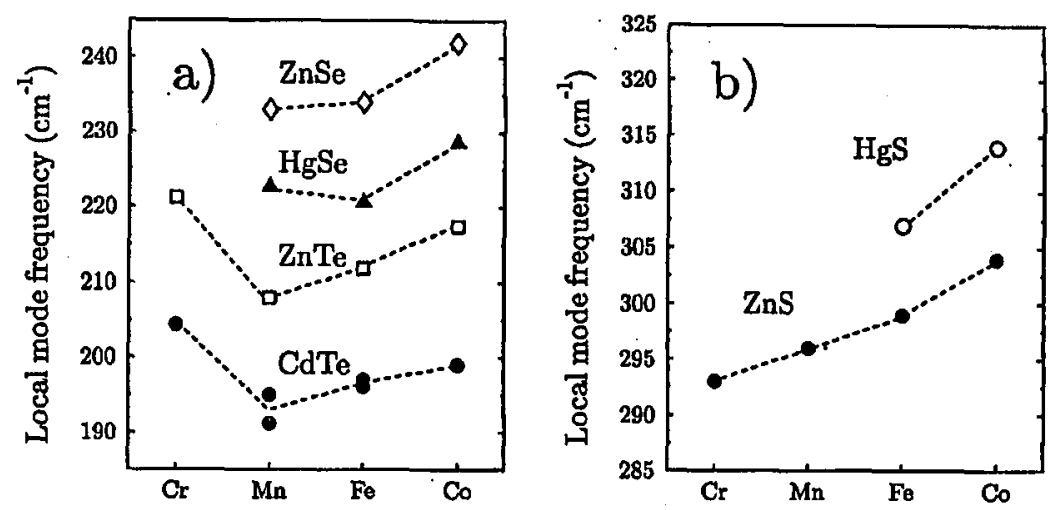

Fig. 1. The local mode frequency of the selected TMIs in some zinc-blende II-VI semiconductors as a number of $3 d$ electrons. (a) Selenides and tellurides: full circles: CdTe $[1,6,7]$, squares: $\mathrm{ZnTe}[1,6]$, full triangles: cubic $\mathrm{ZnSe}[8,9]$, diamonds: HgSe [3, 5] and this work; (b) Sulphides: full circles $\mathrm{ZnS}$ [10], diamonds $\beta$-HgS this work.

under studies local mode frequency minimum can correspond within the experimental error to Mn ion. On the contrary, it seems that for sulphides it could not be true. It is well known that the atomic mass of $\mathrm{Mn}(55)$ is smaller than average atomic mass for $\mathrm{Fe}(56)$ and $\mathrm{Co}(59)$, so one can explain the observed effect by noticeable force constant variation with the number of electrons on $3 d$ shell of the TMI. Taking into account the atomic mass difference for $\mathrm{Fe}$ and Co impurities one can expect a difference between the appropriate force constants equal even to $10 \%$. It is the open question what is the exact reason of such variation. It is very probable that the bonding between the TMI and chalcogenide ion can be affected by the $s p-d$ hybridization. This effect could depend on the chemical nature of both anion and cation. It is also well known that non-monotonic chemical trends across $3 d$ row arise from electron-electron correlations. It seems that for the proper description of the force constant variation the calculations taking into account two above-mentioned phenomena are necessary. More experimental data could also help a lot in the verification of the theoretical predictions. In particular, according to the literature data a $\mathrm{Mn}$ solubility limit in $\mathrm{Hg}_{1-x} \mathrm{Mn}_{x} \mathrm{~S}$ is as high as $x=0.375$. New optical measurements performed on samples with higher than previously analyzed $\mathrm{Mn}$ content should confirm (or reject) a hypothesis about the difference between TMIs behaviour in sulphides and selenides (tellurides).

\section{References}

[1] A.J. Mayur, M. Dean Sciacca, I. Miotkowski, G.C. La Rocca, A.K. Ramdas, S. Rodriguez, Solid State Commun. 91, 785 (1994).

[2] S.W. McKnight, P.M. Amirtharaj, S. Perkowitz, Solid State Commun. 25, 357 (1978); W. Lu, Y. Yu, H.J. Ye, W.L. Xu, K.J. Ma, S.C. Shen, Phys. Rev. B 40, 3383 (1989). 
[3] C.D. Cogurić, Z.V. Popović, D. Stojanović, O. Żiżić, O. Konig, Solid State Commun. 77, 555 (1991); O. Żiżić, Z.V. Popović, A. Milutinović, V.A. Kulbachinskii, Phys. Status. Solidi B 168, K103 (1991); O. Żiżić, Z.V. Popović, V.A. Kulbachinskii, A. Milutinović, Semicond. Sci. Technol. 7, 1484 (1992).

[4] K. Dybko, W. Szuszkiewicz, B. Witkowska, Defect and Diffusion Forum 121-122, 41 (1995).

[5] W. Szuszkiewicz, E. Dynowska, J. Górecka, J. Kachniarz, S. Miotkowska, B. Witkowska, M. Jouanne, C. Julien, M. Balkanski, in: Proc. European Workshop on II-VI Semiconductors and International Workshop on Semimagnetic (Diluted Magnetic) Semiconductors, Eds. H. Heinrich, J.B. Mullin, Trans Tech. Materials Science Form 182-184, 703 (1995).

[6] D.L. Peterson, A. Petrou, W. Giriat, A.K. Ramdas, S. Rodriguez, Phys. Rev. B 33, $1160(1985)$.

[7] W. Lu, H.J. Ye, Z.Y. Yu, S.Y. Zhang, Y. Fu, W.L. Xu, S.C. Shen, W. Giriat, Phys. Status Solidi B 147, 767 (1988); M. Jouanne, C. Testelin, C. Rigaux, A. Mycielski, Solid State Commun. 83, 1061 (1992).

[8] A.K. Arora, E.-K. Suh, U. Debska, A.K. Ramdas, Phys. Rev. B 37, 2927 (1988).

[9] C. Mak, R. Sooryakumar, B.T. Jonker, G.A. Prinz, Phys. Rev. B 45, 3344 (1992).

[10] M. Zigone, R. Beserman, M. Balkanski, in: Light Scattering in Solids, Ed. M. Balkanski, Flammarion, Paris 1972, p. 61; R. Beserman, M. Zigone, M. Balkanski, in: Phonons, Ed. M.A. Nusimovici, Flammarion, Paris 1972, p. 405; M. Zigone, M. Vandevyver, D.N. Talwar, Phys. Rev. B 24, 5763 (1981); A. Anastassadou, E. Liarokapis, E. Anastassakis, S. Stoyanov, Physica Scr. 38, 444 (1988); A. Anastassiadou, E. Liarokapis, E. Anastassakis, Solid State Commun. 69, 137 (1989).

[11] R.G. Alonso, E.-K. Suh, A.K. Ramdas, N. Samarth, H. Luo, J.K. Furdyna, Phys. Rev. B 40, 3720 (1989); E.-K. Suh, A.K. Arora, A.K. Ramdas, S. Rodriguez, Phys. Rev. B 45, 3360 (1992). 